\title{
Prophylactic use of levosimendan in pediatric patients undergoing cardiac surgery: the jury is still out
}

\author{
Xavier Beretta-Piccoli ${ }^{1}$, Dominique Biarent ${ }^{1}$, David De Bels ${ }^{2}$, Patrick M. Honore ${ }^{2}$ and Sébastien Redant ${ }^{1,2^{*}}$ (D)
}

The study by Wang et al. on levosimendan used in prophylaxis of low cardiac output syndrome (LCOS) post-pediatric cardiac surgery is the first study comparing levosimendan versus placebo. The authors did not show an impact on mortality or on the occurrence of LCOS [1]. However, it is very interesting to see that in the multivariate regression analysis, levosimendan had an impact on the onset of LCOS (OR 0.38 and $p=0.037$ ). We are not surprised by the absence of an impact on mortality given the small number of patients. In a Cochrane review, Hummel et al. estimated that the number of pediatric patients required to prove the superiority of levosimendan for outcome mortality was 652 [2]. We wonder how levosimendan could prevent LCOS. LCOS in a heart with good preoperative function is linked to inadequate myocardial protection during aortic clamping, poorly performed cardioplegia, myocardial reperfusion lesions, ventriculotomy, preoperative arrhythmias, activation of inflammatory cascades and complement, and alterations of pulmonary and systemic vascular resistances $[3,4]$. Because of its intrinsic mode of action as a calcium sensitizer, we could expect levosimendan to improve cardiac function after surgery but probably not to prevent intraoperative events. The study of Wang et al. showed the safety of using levosimendan in a population with a preoperative cardiac index of $3.3 \mathrm{ml} / \mathrm{min} / \mathrm{m}^{2}$ and low-risk adjustment in congenital heart surgery (RACHS) [5]. This may lead to another question: are those patients sick enough to show a benefit from levosimendan? The study therefore opens the door to others comparing levosimendan to placebo in more severe pediatric patients with higher RACHS, preoperative decompensation, and/or low cardiac output with a cardiac index $<2.2 \mathrm{~L} \mathrm{~min} / \mathrm{m}^{2}$.

\section{Authors' response}

Anbiao Wang, Chaomei Cui, and Qi Tan

We appreciate the comments of Dr. Sébastien Redant to our recent article regarding the prophylactic use of levosimendan in pediatric patients undergoing cardiac surgery.

The hypothesis that levosimendan is a safe and effective inodilator when used in cardiac surgery could not be supported until now [6]. Levosimendan was found to

This comment refers to the article available at https://doi.org/10.1186/ s13054-019-2704-2.

* Correspondence: Sebastien.redant@huderf.be

'ICU Department, Hôpital Universitaire des Enfants Reine Fabiola HUDERF, Université Libre de Bruxelles, ULB, Av J.J. Crocq 15, 1020 Brussels, Belgium

${ }^{2}$ ICU Department, Centre Hospitalier Universitaire

Brugmann-BrugmannUniversity Hospital, Place Van Gehuchtenplein,4, 1020 Brussels, Belgium

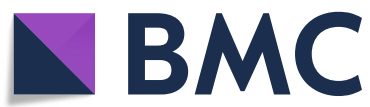

have no impact on mortality or low cardiac output syndrome (LCOS); however, a multivariate regression analysis indicated that levosimendan administration was a risk factor associated with LCOS in our patient cohort.

In the study conducted by Hummel et al., their total 864-patient sample size was calculated based on the incidence of mortality [7]. Different from their study, we elected to focus on LCOS rather than mortality as the primary outcome. This decision was informed by the work of Ricci et al., who found that LCOS occurred in $37 \%$ of patients in their levosimendan group and in $61 \%$ of controls [8]. Based on the more accurate LCOS diagnostic criteria by Cardiac Index (CI), we anticipated 
lower LCOS incidence rates of $45 \%$ and $25 \%$ in the control and levosimendan groups, respectively. We agree that a larger sample size would be preferable, and we are still in the process of collecting clinical data in an effort to extend this study.

Levosimendan was not able to effectively prevent intraoperative events. However, our data indicated that CI significantly deteriorated at $2 \mathrm{~h}$ post-surgery $(2.60 \pm 0.69$ and $2.64 \pm 0.78$, respectively, in the levosimendan and placebo groups). This suggests that the unique pathophysiological changes that occur after surgery are stressful and lead to a high risk of LCOS during this critical period. Considering the inotropic effect, lusitropic effect, and protection against ischemia/reperfusion up to $81 \mathrm{~h}$ of levosimendan and its metabolite $[9,10]$, prophylactic use of levosimendan after cardiac surgery may be a promising and reasonable approach to reducing the risk of subsequent LCOS development. In our experience, levosimendan should not be treated as an emergency medication in the same manner as adrenaline or norepinephrine. As such, once LCOS symptoms including tachycardia or hypotension occurred, levosimendan administration was not recommended.

With respect to concerns regarding whether these patients were sick enough for levosimendan administration, there is currently no consensus as to what a reasonable level of indication is in this context. In addition to referring to risk adjustment in congenital heart surgery (RACHS), we additionally considered lower age, low body weight, and non-cardiac congenital structural abnormalities such as pulmonary arterial hypertension when making our clinical determinations.

In summary, while further research is needed, we are confident in the results of our randomized study and feel that these findings should be an impetus for additional well-designed and focused studies of this topic.

\section{Abbreviations}

LCOS: Low cardiac output syndrome; RACHS: Risk adjustment in congenital heart surgery

\section{Acknowledgements}

None.

\section{Authors' contributions}

$\mathrm{XBP}, \mathrm{DB}$, and SR designed the paper. All authors participated in drafting and reviewing. All authors read and approved the final version of the manuscript.

\section{Funding}

None.

Availability of data and materials

Not applicable.

Ethics approval and consent to participate

Not applicable.

Consent for publication

Not applicable.

\section{Competing interests}

The authors declare that they have no competing interests.

Received: 3 February 2020 Accepted: 26 February 2020

Published online: 23 March 2020

References

1. Wang A, Cui C, Fan Y, Zi J, Zhang J, Wang G, et al. Prophylactic use of levosimendan in pediatric patients undergoing cardiac surgery: a prospective randomized controlled trial. Crit Care. 2019;23(1):428.

2. Hummel J, Rücker G, Stiller B. Prophylactic levosimendan for the prevention of low cardiac output syndrome and mortality in paediatric patients undergoing surgery for congenital heart disease. Cochrane Database Syst Rev. 2017:8:CD011312.

3. Wernovsky G, Wypij D, Jonas RA, Mayer JE Jr, Hanley FL, Hickey PR, et al. Postoperative course and hemodynamic profile after the arterial switch operation in neonates and infants. A comparison of low-flow cardiopulmonary bypass and circulatory arrest. Circulation. 1995;92(8):2226-35.

4. Bailey JM, Hoffman TM, Wessel DL, Nelson DP, Atz AM, Chang AC, et al. A population pharmacokinetic analysis of milrinone in pediatric patients after cardiac surgery. J Pharmacokinet Pharmacodyn. 2004;31(1):43-59.

5. Jenkins KJ, Gauvreau K, Newburger JW, Spray TL, Moller JH, lezzoni LI. Consensus-based method for risk adjustment for surgery for congenital heart disease. J Thorac Cardiovasc Surg. 2002;123(1):110-8.

6. Guarracino F, Heringlake M, Cholley B, Bettex D, Bouchez S, Lomivorotov W, et al. Use of levosimendan in cardiac surgery: an update after the LEVO-CTS, CHEETAH, and LICORN trials in the light of clinical practice. J CardiovasC Pharmacol. 2018;71(1):1-9.

7. Hummel J, Rucker G, Stiller B. Prophylactic levosimendan for the prevention of low cardiac output syndrome and mortality in paediatric patients undergoing surgery for congenital heart disease. Cochrane Database Syst Rev. 2017;8:D11312.

8. Ricci Z, Garisto C, Favia I, Vitale V, Di Chiara L, Cogo PE. Levosimendan infusion in newborns after corrective surgery for congenital heart disease: randomized controlled trial. Intensive Care Med. 2012;38(7):1198-204.

9. Maack C, Eschenhagen T, Hamdani N, Heinzel FR, Lyon AR, Manstein DJ, et al. Treatments targeting inotropy. Eur Heart J. 2019;40(44):3626-3644.

10. Antila S, Kivikko M, Lehtonen L, Eha J, Heikkila A, Pohjanjousi P, et al. Pharmacokinetics of levosimendan and its circulating metabolites in patients with heart failure after an extended continuous infusion of levosimendan. Br J Clin Pharmacol. 2004;57(4):412-5.

\section{Publisher's Note}

Springer Nature remains neutral with regard to jurisdictional claims in published maps and institutional affiliations. 